\title{
Children with Special Needs in School Activities
}

Miray Hande ${ }^{1}$, Fahriye Burcu ${ }^{1}$, Hazal Mertz ${ }^{1}$

${ }^{1}$ Department of Technology and Education, Africa University, Zimbabwe

*Corresponding Author: Miray Hande

Received: November 28, 2020

Revised: December 12, 2020

Accepted: December 18, 2020

\begin{abstract}
Not every child born in this world always experiences normal development. Many of them experience obstacles, disturbances, delays, or have risk factors so that to achieve optimal development, special treatment or intervention is required. This group became known as children with special needs or extraordinary children. In understanding children with special needs or outside children, it is necessary to have an understanding of the types of disabilities (children with special needs) and the consequences that occur to sufferers. Children with special needs are referred to as children with disabilities because they include children whose growth and development experience deviations or abnormalities, both physically, mentally, emotionally, and socially when compared to normal children.
\end{abstract}

Keywords: Special Needs, Disabilities, Abnormalities

\section{Introduction}

The specific characteristics of children with special needs are generally related to the level of functional development. These specific characteristics include the level of sensory motor development, cognitive development, language skills, self-skills, self-concept, social interaction skills, and creativity. There are differences in the characteristics of each student with special needs, which will require special teacher skills. Teachers are required to have the ability to relate by combining the abilities and talents of each child in several aspects. These aspects include the ability to think, see, hear, speak, and how to socialize. These things are directed at the success of the ultimate goal of learning, namely changes in behavior towards maturity.

\section{Understanding Children with Special Needs}

According to Hallahan and Kauffman, 198 Children with special needs (formerly known as extraordinary children) are defined as children who need special education and services to develop their perfect human potential. The mention of a child with special needs, because in meeting his needs, this child needs assistance with educational services, social services, guidance and counseling services, and various other types of services that are special in nature. In everyday conversations, children with special needs are dubbed "extraordinary people", because they have extraordinary advantages, for example, people who are known to have extraordinary intellectual abilities, have high creativity in producing extraordinary findings in the field of science and technology, religious, and in other areas of life (Stow \& Selfe, 2018).

In the world of education, the word extraordinary is also a nickname or designation for those who have deficiencies or experience various disorders and deviations that are not 
experienced by normal people in general. The abnormality or deficiency can be in the form of physical, psychological, social and moral abnormalities.

The definition of "extraordinary" in the world of education has a broader scope than the meaning of "disabilities or disabilities" in everyday conversation. in the world of education the term extraordinary implies a double meaning, namely those who deviate upwards because they have extraordinary abilities compared to normal people in those who are generalized and those who deviate downward, namely those who suffer from disabilities or disabilities and deficiencies that are not suffering by normal people in general (Amillategui et al., 2007; Amillategui et al., 2009; Umarova, 2020). Examples of people who deviate upward in terms of intellectual abilities (brain), for example professor BJ Habibie, because he has intelligence above normal people and intellectual abilities in the field of world-class "aerodynamics" so that he is dubbed a genius in his field, while examples people who stray downward are people who are slow and difficult to learn.

\section{Types of Children with Special Needs}

In the world of education, children with special needs are classified into several groups according to the type of disability of the child. The following will explain several types of children with special needs. Children who have sensory deficiencies, namely the sense of sight. Even though their sense of sight is problematic, their intelligence is still normal. The things related to the eye are replaced by other senses in compensation. Children who have hearing impairments. They have difficulty interacting and socializing with other people towards the environment, including education and teaching (Heward et al., 2006). Deaf children are divided into 2, namely, deaf (the deaf), and deaf (hard of hearing). A child who has a disorder in his body, namely paralysis. Children who experience this paralysis are caused by polio and disorders of their motor nerves. Children who have abnormalities in the speaking or language process. Children like this have difficulty in speaking or speaking so that they cannot be understood by others. Children who experience disturbances at their emotional level. This is related to psychological problems. Children who experience this emotional disorder are divided into 2 types, namely: Behavioral Disorders, the characteristics are: (1) Disruptive in class (2) Impatient, too quick to act (3) Disrespect for others, (4) Like to oppose, (5) Blaming others, (6) Often daydreaming. Attention Deficit Disorder (ADD / Attention Deficit Disorder), the symptoms of which occur for at least 6 months. These symptoms include: (1) Not listening to other people talking, (2) Often failing to pay attention to certain objects (3) Often not carrying out orders from other people.

Children with hyperactivity (ADHD / Attention Deficit with Hiperactivity Disorder), the symptoms are: (1) unable to stay still, (2) inability to pay attention long enough (3) hyperactivity (4) awkward.Keterbelakangan Mental

Children who have very low mental levels always need help from others because they are unable to take care of themselves, have limited intelligence, are apathetic, and have unstable attention. Based on their intelligence, mentally retarded children are divided into several parts, namely: (a) Idiot, which is the child with the lowest level of intelligence (IQ> 20). Whose mental development will not increase beyond the age of 3 years, even though basically he is a teenager or an adult. (b) Imbesil, namely children who have (IQ 20-50), mental development can reach the age of 7 years, can be taught to take care of themselves in the most simple needs. (c) Debil or moron, namely children who have (IQ 50-70), Debil 
underdevelopment is not as bad as the two types above. The development of the soul can take up to $101 / 2$ years. This Debile man could meet his own needs.

\section{Psychoneurosis}

Children who experience psychoneurosis are basically normal children. They only experience continuous personal tension, besides that they cannot solve their own problems so that the tension does not subside. This psychoneurosis is divided into 3, namely: (a) Worry psychoneurosis is a child who has excessive anxiety and does not reasoned. (b) Hysterical, is a child who unconsciously paralyzes one of his limbs, as a matter of fact organically, there is no abnormality. (c) Obsessive psychoneurosis, is a child who has certain thoughts and urges continuously. Psychosis is also called a major personality disorder because the entire personality of the person concerned is affected and the person cannot live a normal life. Psychopaths Is a behavior disorder, meaning that psychopathic sufferers cannot care about social norms. They always do their own way without considering the interests of others, so they often harm others. And people with psychopathy are not aware of any abnormalities in themselves.

\section{Causes of Children with Special Needs}

There are three factors that cause children with special needs, namely: (1) Pre-Christmas events (in the womb), various diseases that can cause abnormalities in the fetus when pregnant women include: (a) Blood poisoning (Toxaenia) in pregnant women can cause the fetus to not receive oxygen optimally, thus affecting the nerves of the brain which can cause disruption of the nervous system and deafness in infants. (b) Infection due to dirty diseases (genital disease / syphilis suffered by the father or mother), toxoplasmosis (from animal viruses such as cat hair), trachma and tumors. Tumors can occur in the brain related to the sense of sight due to damage to the eyeball and hearing resulting from damage to the membrane of the ear drum. Lack of vitamins or excess iron so that the mother is poisoned which results in abnormalities in the fetus that causes eye problems. Also damage to the brain, causing impaired function of thinking or verbal communication, damage to the ear organs resulting in loss of hearing function. (2) Christmas (time of birth) At the time of birth which may only take a short amount of time but if improper handling will threaten the development of the baby. Among them are: (a) premature birth, (b) forced birth using a vacuum, (c) birth process of breech babies. (3) Post Natal (after birth) Various events experienced in his life can often result in a person losing a function of organs or muscle and nerve functions. You can even lose the organ itself. The causes of deafness that occur after birth include: (1) Incidents occur, (2) Vitamin or nutritional deficiency, (3) fever and convulsions (Avramidis et al., 2000; Narzisi, 2020).

\section{How to Deal with Children with Special Needs}

It is undeniable that caring for children with special needs requires additional energy, thought, and higher costs than caring for children in general. The following will explain the steps in dealing with children with special needs, including the following: (1) Strengthening the mental condition of parents this strategy requires the active role of parents in caring for children with special needs. Some of the strategies needed by parents of children with special needs include the need to provide time for themselves, cooperate in parenting with partners, and be active in seeking information about children with special needs. Parents need to provide time for themselves, as a form of appreciation for themselves who have provided 
extra time and daily energy to care for children with special needs (ElZein, 2009; Stella et al., 2004).

\section{Adequate Social Support}

Social support plays an extraordinary role for the sustainability of caring for children with special needs. Social support can be in the form of moral encouragement, which strengthens the surrounding community and immediate family. Through social support, it is hoped that parents of children with special needs can share experiences about parenting for children with special needs. This has not been seen much in our society, given the strong belief that having children with special needs is a "karma" from God. Thus, there is a tendency for families with children with special needs to be "ostracized" by society. To eliminate this trend, it is necessary for the role of the government to provide education to the general public about children with special needs. This education can be delivered through media channels or community service posts to reach people in rural or rural areas (Čagran \& Schmidt, 2011).

\section{Active Role of Government}

The government's active role in providing health services and consultations that are accessible to the public. This is a very vital factor for the general public, especially for those in the middle to lower social class. It is undeniable that consultation and health services are still something that is expensive. By providing consultations for children with special needs that are easily accessible to the community, it is hoped that children with special needs will receive consultation services that are easy and inexpensive. The government also has to provide facilities for handling children with special needs in an integrated manner. Currently, the government has paid attention to children with special needs through the formation of the Directorate of Special School Development under the coordination of the Ministry of Education and Culture (Lewis, 2002).

\section{How to Teach Children with Special Needs}

Practical Ways in teaching Children with Special Needs contain information that supports the teaching methods of teachers (Boling, 2007). Teachers must attend practical and comprehensive training in inclusive education in order to better understand and implement the strategies used in inclusive education. The ways to teach children with special needs are as follows: (1) Be kind and positive, (2) Use appropriate classroom settings, (3) Speak clearly with your face facing students, (4) Use all communication methods, (5) Use efficient teaching strategies (6) Prioritize peer support (7) Make the best use of available teaching materials (8) Explain to all children about disabilities (9) Make your class as accessible as possible and (10) Share experiences. All of these teaching principles can also be applied to regular classes.

\section{Conclusion}

Children with special needs (formerly known as extraordinary children) are defined as children who need special education and services to develop their perfect human potential. The mention of a child with special needs is because in meeting their needs, this child needs assistance with educational services, social services, guidance and counseling services, and various other types of special services. In handling children with special needs, there are three things that need to be considered, including strengthening the mental condition of parents who have children with special needs, strong social support from neighbors and the 
environment around these children with special needs, and the last is the active role of the government in making services health and consultation for children with special needs.

\section{References}

Amillategui, B., Calle, J. R., Alvarez, M. A., Cardiel, M. A., \& Barrio, R. (2007). Identifying the special needs of children with Type 1 diabetes in the school setting. An overview of parents' perceptions. Diabetic Medicine, 24(10), 1073-1079.

Amillategui, B., Mora, E., Calle, J. R., \& Giralt, P. (2009). Special needs of children with type 1 diabetes at primary school: perceptions from parents, children, and teachers. Pediatric diabetes, 10(1), 67-73.

Avramidis, E., Bayliss, P., \& Burden, R. (2000). A survey into mainstream teachers' attitudes towards the inclusion of children with special educational needs in the ordinary school in one local education authority. Educational psychology, 20(2), 191-211.

Boling, E. (2007). "Yeah, but I still don't want to deal with it". Changes in a Teacher Candidate's Conceptions of Inclusion. Teaching Education, 18(3), 217-231.

Čagran, B., \& Schmidt, M. (2011). Attitudes of Slovene teachers towards the inclusion of pupils with different types of special needs in primary school. Educational Studies, 37(2), 171-195.

ElZein, H. L. (2009). Attitudes toward inclusion of children with special needs in regular schools (A case study from parents perspective). Educational Research and Reviews, 4(4), 164-172.

Heward, W. L., \& Wood, C. L. (2006). Exceptional children: An introduction to special education. Pearson Education/Merrill/Prentice Hall.

Lewis, A. (2002). Primary special needs and the national curriculum. Routledge.

Narzisi, A. (2020). Handle the autism spectrum condition during Coronavirus (COVID-19) stay at home period: Ten tips for helping parents and caregivers of young children.

Stella, M. Y., Nyman, R. M., Kogan, M. D., Huang, Z. J., \& Schwalberg, R. H. (2004). Parent's language of interview and access to care for children with special health care needs. Ambulatory pediatrics, 4(2), 181-187.

Stow, L., \& Selfe, L. (2018). Understanding children with special needs, (Vol. 52). Routledge.

Umarova, Z. (2020). Modern and Innovative Approaches to the Organization of Students' Self-Education in Higher Educational Institutions. Journal La Edusci, 1(4), 5-8. 